\title{
Relaxation Progressive Muscle Program on Exercise Behavior and Clinical Outcomes among Hypertension Patients
}

\author{
Rian Adi Pamungkas ${ }^{1}$, Wahyu Kirana ${ }^{2}$ Florensa $^{3}$ \\ ${ }^{1,2,3}$ Yarsi Nursing College, Pontianak, Indonesia
}

\begin{tabular}{l}
\hline \hline Article Info \\
\hline Article history: \\
Received May 9, 2016 \\
Revised Jul 18, 2016 \\
Accepted Jul 30, 2016 \\
\hline
\end{tabular}

Keyword:

Blood pressure level Cholesterol total level

Exercise behavior

Hypertension

Relaxation progressive muscle program

\begin{abstract}
The objective of this study was to examine the effect of relaxation progressive muscle program on exercise behavior and clinical outcomes among Patients with Hypertension in a Community Setting, in Indonesia. A quasi-experimental, two group, pre-test and post-test design was used in this study. The experimental group received relaxation progressive muscle program, whereas the control group did not receive the program. 30 subjects in the experimental group and 30 subjects in the control group completed the program, respectively. The results of this study indicated that significantly differences on exercise behavior $(\mathrm{p}=0.000)$, blood pressure level $(\mathrm{p}=0.000)$ and cholesterol total level $(\mathrm{p}=0.000)$ between the experimental group and control group. The relaxation progressive muscle program was absolutely effective to improve the exercise behavior, blood pressure level and cholesterol total level among patients with hypertension. Further studies should be recognized by using larger groups over a longer time frame and Health care providers also should focus in promoting this program among patients with hypertension
\end{abstract}

Copyright (c) 2016 Institute of Advanced Engineering and Science. All rights reserved.

\section{Corresponding Author:}

Rian Adi Pamungkas, Yarsi Nursing Collage, Pontianak, Indonesia.

Email: adirian491@yahoo.com

\section{INTRODUCTION}

The high percentage of hypertension has become a universal phenomenon in the world. The World Health Organization (WHO), 2011 reported that more than 1 million people have been diagnosed with hypertension. In Indonesia, diagnosis of Hypertension reached 26.5\% adults.

Several factors contributed to hypertension, including family history, advanced age, gender-related risk patterns, weight, poor diet and lack of physical inactivity [1]. These factors are reported to be barriers to managing patients with hypertension and to contribute a major risk factor for the development of complications.

Hypertension is associated with serious multiple long time complications, such as stroke, heart diseases, and peripheral vascular diseases. Hypertension is also associated with death where nearly8 million in the world every year. Prevention of Hypertension complication is important to improve the quality of life of the population. Hypertension management related with non-pharmacology treatment has been stated as a potential foundation to improve the blood pressure level. Effective management of exercise behaviors has benefits for the patients.

Despite the study of Ramba (2005) showed significantly positive effects in blood pressure level. However, participants still reported some barriers toward exercise behavior. In addition, the previous researcher conducted the study with the small sample and did not measure the exercise behavior and total cholesterol level. For testing the feasibility of the program, the researcher will conduct this study to focus on 
the effectiveness of relaxation progressive muscle program on blood pressure level and cholesterol level among patients with hypertension in a community setting.

The objective of this study was to compare the effect of relaxation progressive muscle program on exercise behavior and clinical outcomes who has received the relaxation progressive muscle program than those patients who are not receiving the program among patients with hypertension in Indonesia

\section{RESEARCH METHOD}

This study was a quasi-experimental design, two groups, pre-test and post-test design. It was conducted to test the effect of relaxation progressive muscle program on exercise behavior and clinical outcomes among patients with hypertension. The participants were selected by randomly assigned to the experimental and control groups. The experimental group received the relaxation progressive muscle program, whereas the control group did not receive the program.

\subsection{Samples}

This study was conducted in a community setting, Majene Sub-district, West Sulawesi Province, Indonesia. Patients who met the inclusion criteria were selected including: (1) Patients who has been diagnosed with hypertension, (2) stayed in a community setting, Majene Sub-District, West Sulawesi Province, Indonesia, (3) 35-75 years old, (4) be able to communicate by Indonesian language, both verbal and written, (5) have no vision impairment, hearing impairment and no movement impairment. Whereas, patients who had severe complications that caused the patients to be unable to continue participating in this study and patients with severe hypertension $(>200 \mathrm{mmHg}$ ) were excluded. The samples size was calculated based on a significance level of alpha $=0.05$, power $=0.80$ and $d=0.80$. Forty patients were required for both the experimental and control groups.

\subsection{Instruments}

Three instruments were used to collect the data in this study, including Demographic Data Questionnaire and Health Information (DDQHI), the Exercise Behaviors Questionnaire (EBQ), and Clinical Outcomes Parameter which were used to measure the blood pressure level and cholesterol total level.

The patients were required to fill out the form after providing an informed consent. The Demographic Data consisted of 6 items including patient's name, age, gender, occupation, education, and family income. The Health Information consisted of 3 items including blood pressure level, cholesterol total level, and BMI status.

The exercise behavior questionnaire (EBQ) was used to measure the exercise behaviors of the patients with hypertension. It was modified based on existing tools by Pamungkas, Cinnawong, \& Kritpracha (1992). This instrument consists of 18 items, each item was measured by using a five-point (0-4) liker scale in which the positive statement, including $0=$ never, $1=$ seldom, $2=$ occasionally, $3=$ often, and $4=$ repeatedly. The total score is from 0-72 with the scoring system being poor (score 0-25), moderate (score 26-52), and well (score 53-72) with the highest score indicating more the frequency of exercise behaviors.

In this study, the clinical outcomes were divided to be the level of blood pressure (BP) and total cholesterol level. be the level of blood pressure (BP) was measured by using a mercury sphygmomanometer. Whereas, total cholesterol level was tested by using an automatic lipid pro-meter.

\subsection{Ethical considerations}

This study was conducted consistently, protecting the human rights of all of the participants. The permission letter has been obtained from the Head of the Health Department, Majene Sub-district and the Head of Public Health Center of Pamboang, Majene Sub-district, West Sulawesi, Indonesia. The patients also received information regarding his/her right to withdraw at any time during participation this study without any negative consequences. Important information was explained to the patients related with purpose of the study, procedures, risk, and benefits of the study. The confidentiality of the patients was maintained throughout the study.

\subsection{Statistical analysis}

The SPSS 16.0 software package program were used to analyze in this study with the significance level set at an alpha of .05. Descriptive statistics were used to analyze the demographic characteristics and clinical characteristics. Whereas an independent t-test was used to compare pre-test and post-test mean score of the blood pressure level and cholesterol total level of the patients between the experimental and control group. 


\section{RESULTS}

\subsection{The demographic characteristics of the patients}

A total of 40 patients with hypertension were enrolled in the study, 20 patients were allocated to the experimental group and 20 patients in the control group. The baseline characteristics of both groups were similar. The largest percentage of the subjects both of group in the experimental group and control group were categorized as middle age (34-59 years old) $(80.0 \%)$. More than half of subjects in the experimental group $(80.0 \%)$ and control group $(80 \%)$ were female whose had studied to elementary school level $(40 \%)$ in the experimental group and control group $(35 \%)$. The majority of the patients in the experimental group reported that their monthly income was $<1,000,000$ IDR (or $<84$ USD) (60\%), whereas for the control group was $<1,000,000$ IDR (or $>84$ USD) (50). For the occupational status, the majority of the patients in the experimental group (90\%) and control group (95\%) worked as Non-healthcare related worker (Table 1).

Table 1. Frequencies and Percentages of Demographic Data for the Experimental and Control Group

\begin{tabular}{|c|c|c|c|c|c|c|}
\hline \multirow{2}{*}{ Characteristics } & \multicolumn{2}{|c|}{$\begin{array}{l}\text { Experimental Group } \\
\qquad(\mathrm{n}=20)\end{array}$} & \multicolumn{2}{|c|}{$\begin{array}{l}\text { Control Group } \\
\quad(\mathrm{n}=20)\end{array}$} & \multirow[t]{2}{*}{$x^{2}$} & \multirow{2}{*}{$p$} \\
\hline & $\mathrm{N}$ & $\%$ & $\mathrm{n}$ & $\%$ & & \\
\hline Age (Min-Max = 26-70) & $\mathrm{M}=53.91$ & $\mathrm{SD}=.50$ & $\mathrm{M}=54.34$ & $\mathrm{SD}=.63$ & $1.90^{\mathrm{a}}$ & 0.75 \\
\hline Young age (20-33 years old) & 0 & 0 & 0 & 0 & & \\
\hline Middle age (34-59 years old) & 16 & 80 & 16 & 80 & & \\
\hline Elderly (60-80 years old) & 4 & 20 & 4 & 0 & & \\
\hline Gender & & & & & $0.037^{\mathrm{a}}$ & 0.84 \\
\hline Male & 4 & 20 & 4 & 20 & & \\
\hline Female & 16 & 80 & 16 & 80 & & \\
\hline Occupation & & & & & $0.062^{\mathrm{a}}$ & 0.8 \\
\hline Healthcare related worker & 2 & 10 & 1 & 5 & & \\
\hline Non-healthcare related worker & 18 & 90 & 19 & 95 & & \\
\hline Educational level & & & & & $8.95^{\mathrm{a}}$ & 0.44 \\
\hline Elementary school & 8 & 40 & 7 & 35 & & \\
\hline Junior high school & 4 & 20 & 3 & 15 & & \\
\hline Senior high school & 1 & 5 & 1 & 5 & & \\
\hline Diploma & 4 & 20 & 2 & 10 & & \\
\hline Bachelor & 3 & 15 & 7 & 35 & & \\
\hline Monthly income & & & & & $2.01^{\mathrm{a}}$ & 0.15 \\
\hline$<1,000,000 \mathrm{IDR}(<84 \mathrm{USD})$ & 12 & 60 & 10 & 50 & & \\
\hline$>1,000,000$ IDR (> 84 USD) & 8 & 40 & 10 & 50 & & \\
\hline
\end{tabular}

\subsection{The clinical characteristic of the patients}

Table 2 shows that mean systolic blood pressure of both groups was categorized as hypertension, the level of blood pressure both experimental and control groups were $(150 \mathrm{mmHg})(151 \mathrm{mmHg})$ respectively. Whereas, the mean cholesterol level for the experimental group was $207 \mathrm{mg} / \mathrm{dl}(\mathrm{SD}=57.5)$ and was 210 $\mathrm{mg} / \mathrm{dl}(\mathrm{SD}=44.4)$ for the control group. For BMI of the patients, both of experiment and control groups was close to overweight levels, 23 of the experimental group and 23.2 of the control group, respectively. Statistically, there was no significant difference in clinical characteristics of the subjects between the experimental and control group (Table 2).

Table 2. Frequencies and Percentages of Clinical Characteristic of the Patients for the Experimental and Control Group ( $\mathrm{N}=40)$

\begin{tabular}{|c|c|c|c|c|c|c|}
\hline Characteristics & \multicolumn{2}{|c|}{$\begin{array}{l}\text { Experimental Group } \\
\qquad(\mathrm{n}=20)\end{array}$} & \multicolumn{2}{|c|}{$\begin{array}{l}\text { Control Group } \\
(\mathrm{n}=20)\end{array}$} & $x^{2}$ & $P$ \\
\hline Sistolic Blood Pressure & $M=150$ & $\mathrm{SD}=21.52$ & $\mathrm{M}=151$ & $\mathrm{SD}=13.33$ & $18.17^{\mathrm{a}}$ & 0.956 \\
\hline Cholesterol Level & $M=207$ & $\mathrm{SD}=57.5$ & $M=210$ & $\mathrm{SD}=44.4$ & $40^{\mathrm{c}}$ & 0.68 \\
\hline BMI & $M=23$ & $\mathrm{SD}=3.86$ & $M=23.2$ & $\mathrm{SD}=3.64$ & $0.95^{\mathrm{c}}$ & 0.34 \\
\hline
\end{tabular}




\subsection{The effect of relaxation progressive muscle program on exercise behaviors}

An independent t-test was used to examine the differences in the pre-test and post-test exercise behaviors scores between two groups. Table 3 describes that the mean total of the pre-test for exercise behaviors scores for both groups not statistically different $(t=0.93, \mathrm{p}>0.05)$. However, the total of post-test exercise behaviors scores between the patients in the experimental group was statistically higher than those patients in the control group $(\mathrm{t}=10.71, \mathrm{p}<0.05)$.

Table 3. Pre-test and Post-test Exercise Behaviors Scores between the Experimetal Group and Control Group $(n=40)$

\begin{tabular}{|c|c|c|c|c|c|c|}
\hline \multirow[t]{2}{*}{ Variable } & \multicolumn{2}{|c|}{$\begin{array}{l}\text { Experimental Group } \\
\qquad(\mathrm{n}=20)\end{array}$} & \multicolumn{2}{|c|}{$\begin{array}{l}\text { Control Group } \\
\quad(\mathrm{n}=20)\end{array}$} & \multirow[t]{2}{*}{$t$} & \multirow[t]{2}{*}{$p$} \\
\hline & M & SD & M & SD & & \\
\hline \multicolumn{7}{|l|}{ Exercise Behaviors } \\
\hline Pre-test exercise behavior score & 34.00 & 16.83 & 31.46 & 13.80 & 0.93 & 0.32 \\
\hline Post-test exercise behavior score & 65.54 & 10.10 & 37.60 & 12.80 & 10.71 & 0.00 \\
\hline
\end{tabular}

Note: $\mathrm{df}=38, \mathrm{p}<0.05$

The effect of relaxation progressive muscle program on blood pressure level and cholesterol level were also examined by comparing the mean scores. The results revealed that the mean scores of blood pressure level $(\mathrm{t}=-1.22, \mathrm{p}=0.00)$ and total cholesterol level $(\mathrm{t}=-0.698), \mathrm{p}=0.00)$ of the subjects in the experimental group were significantly lower than those in the control group (Table 4).

Table 4. Pre-test and Post-test Blood Pressure Level Scores Between the Experimental Group and Control Group $(\mathrm{N}=40)$

\begin{tabular}{|c|c|c|c|c|c|c|}
\hline \multirow[t]{2}{*}{ Variable } & \multicolumn{2}{|c|}{$\begin{array}{l}\text { Experimental Group } \\
\qquad(\mathrm{n}=20)\end{array}$} & \multicolumn{2}{|c|}{$\begin{array}{l}\text { Control Group } \\
\qquad(\mathrm{n}=20)\end{array}$} & \multirow[t]{2}{*}{$t$} & \multirow[t]{2}{*}{$P$} \\
\hline & $\mathrm{M}$ & SD & M & SD & & \\
\hline \multicolumn{7}{|l|}{ Sistolic blood pressure level } \\
\hline Pre-test sistolic blood pressure & 150 & 21.521 & 151 & 13.33 & -1.22 & 0.00 \\
\hline Post-test sistolic blood pressure & 136 & 19.029 & 153.5 & 7.45 & & \\
\hline \multicolumn{7}{|l|}{ Diastolic blood pressure level } \\
\hline Pre-test diastolic blood pressure & 93 & 10.809 & 90.5 & 8.25 & -0.698 & 0.00 \\
\hline Post-test diastolic blood pressure & 82.50 & 5.501 & 91.5 & 8.12 & & \\
\hline
\end{tabular}

Note: $\mathrm{df}=65.57,{ }^{*} \mathrm{p}<0.05$

With regard to the comparison of total cholesterol between experimental and control group showed that the mean total of the pre-test for total cholesterol level scores both groups not statistically different $(p>0.05)$. However, the total of post-test total cholesterol level scores between patients in the experimental group was statistically higher than those patients in the control group $(\mathrm{p}<0.05)$ (Table 5).

Table 5. Pre-test and Post-test Blood Pressure Level Scores between the Experimental Group and Control

$$
\text { Group }(\mathrm{N}=40)
$$

\begin{tabular}{|c|c|c|c|c|c|c|}
\hline \multirow[t]{2}{*}{ Variable } & \multicolumn{2}{|c|}{$\begin{array}{l}\text { Experimental Group } \\
(\mathrm{n}=20)\end{array}$} & \multicolumn{2}{|c|}{$\begin{array}{l}\text { Control Group } \\
\quad(\mathrm{n}=20)\end{array}$} & \multirow[t]{2}{*}{$t$} & \multirow[t]{2}{*}{$P$} \\
\hline & $\mathrm{M}$ & $\mathrm{SD}$ & $\mathrm{M}$ & SD & & \\
\hline \multicolumn{7}{|l|}{ Total Cholesterol Level } \\
\hline Pre-test Total Cholesterol & 205.14 & 57.45 & 210.10 & 44.48 & -0.407 & 0.68 \\
\hline Post-test Total Cholesterol & 179.11 & 33.16 & 199.09 & 29.99 & 2.64 & 0.01 \\
\hline
\end{tabular}

Note: $d f=65.57, * p<0.05$

\subsection{Discussions}

The discussion of this study focuses on two parts based on the result and hypothesis of this study which include: characteristics of the subjects and hypothesis testing of the effectiveness of the relaxation progressive muscle program on blood pressure level and cholesterol total level among patients with hypertension. 


\subsection{Characteristics of the subjects}

Most of subject in both groups were females: experimental group (80.0\%) and control group $(80.0 \%)$. Females are considered to be at risk of developing hypertension poor nutrition and other lifestyle risk factors which increased susceptibility to hypertension [2]. Similarly, previous studies also found that the proportion of hypertension in women is more likely increase two times faster compared the man. Less adequate control of blood pressure is associated with a greater increase in body mass index and less physically active regarding controlling their diseases [3]. More than $90 \%$ of the subjects in the experimental group and control group have an occupation as Non-healthcare related worker worked with a total monthly income were greater than 1,000,000 IDR per month ( $\geq 84$ USD).

With regard to the clinical characteristics, most of the patients in this study were categorized as hypercholesterolemia (Cholesterol $\geq 200 \mathrm{mg} / \mathrm{dl}$ ). These results were similar to the previous study reported that patients with high total cholesterol are much more likely to develop high blood pressure [4]. The average BMI of the patients was $23(\mathrm{SD}=3.86)$ in the experimental group and $23.2(\mathrm{SD}=3.64)$ in the control group. This finding was indicated that the BMI of the patients was at the normal borderline. This result was consistent to previous study reported that higher BMI has a correlation for men but not for men, it was caused a woman have twice the percent body fat at a given BMI than men and appear to regulate related hormones, like leptin, at a different level.

In conclusion, most of the patients were females who have an average age in the range of 34 to 59 years (middle age). They have been diagnosed hypertension with high total cholesterol level and BMI status. It was indicated that the demographic and clinical characteristics of the patients in this study were accurate representations of patients' hypertension in Indonesia. Statistically, there were no significant differences in demographic characteristics and clinical characteristics between the experimental group and control group.

\subsection{Analysis the effect of relaxation progressive muscle program exercise behavior}

The findings confirmed the hypothesis of this study that intended to answer the effectiveness of the relaxation progressive muscle program on exercise behaviors. The total mean scores of exercise behavior among patients with hypertension in the experimental group after receiving the program were significantly than those in the control group. Possible reasons of the improvement of exercise behavior including:

Firstly was application of the program. The program of this study was developed based on self-efficacy model by Bandura (1994) [5]. Self-efficacy could be a foundation for empowering patients to increase physical, psychological, and behavioral change in order to live with hypertension to monitor one's condition and to deal with cognitive, behavioral, and emotional responses to maintain quality of life. Selfefficacy also can influence personal confidence to routinely take active exercise. This finding is consistent with a previous study which stated that self-efficacy was significantly increase exercise adherence and exercise self-efficacy among older people [6].

Secondly, individual education, individual counseling and group discussion each week. The education session was conducted to gain more knowledge. It was focused on delivering the general information related to hypertension, signs and symptoms of hypertension, complications, and the importance of relaxation progressive muscle intervention for managing hypertension

The third reason is related to the goal setting and action planning strategy. The goal setting and action planning strategy can help the patients to intentionally take responsibility and engage in influencing the dietary and exercise behaviors with their own achievable goals and feasible action plans. The measurable, specific, clear, and short period goals and action plan also can provide clear guidance to the patients in regard what activities should be done and how many times to achieve the behaviors based on recommendations and also anticipate the possibility barriers which potentially violate the goals achievement [7]. The main objective of the appropriate goal setting and an action plan is to increase the self-confidence of the patients, in order to be able to commit the goal.

The fourth reason is related with face to face follow-up. During participating in the program, patients received a face to face follow up in a public health center before starting the program. This follow-up for evaluating goals achievement, assessing the problem and creating problem-solving. In the last week, they received a face to face follow-up for evaluating the overall achievement and assessing the clinical outcomes. In addition, researcher motivated and facilitated patients to continue the program. During this process, the researcher gave praise and reinforcement for patients with affirmations. This method influenced the patient's confidence and expectations to maintain the positive behavior.

The fifth reason related to social support. In this study, patients met researcher, nurses and other patients in the public health center. The collaboration of the community health volunteers symbolizes a social support which benefits the patient's behavioral change. Good social support has a vital role in patients performing good dietary and exercise adherence. Families or friends must be aware, supportive and should try to avoid scheduling events which may interfere with exercise time. This can help to avoid any potential 
conflicts or distractions that will affect of exercise adherence. This finding was also consistent with a previous study confirmed that active behaviors exercise was associated with social support care [8]. In addition, patient's preferences also had a positive impact of influence exercise adherence and maximize outcomes [9].

\subsection{Analysis the effect of relaxation progressive muscle program on blood pressure level and cholesterol total level}

The present of this study stated that the blood pressure and cholesterol level of the patients in the experimental group among patients with hypertension showed that significant reduction after participating the relaxation progressive muscle program than those of the control group. The results were similar to the previous study which found that the blood pressure and total cholesterol total level of the subjects in the experimental group had statistically significant decrease compared to the patients in the control group $(\mathrm{p}<0.05)[10]$.

The increased level of exercise behavior in the experimental group indicated that the relaxation progressive muscle program may be effective in decreasing the level of blood pressure level and total cholesterol total level. Patients in the experimental group were encouraged to perform regularly relaxation progressive muscle program to improve exercise behavior at least 150 minutes per week by warming up before exercise, progressive muscle by relaxing. Exercise behaviors might decrease the blood pressure and cholesterol total level status by increasing the uptake of blood glucose in the muscle [11]. Similarly, the previous study found that exercise can improve blood pressure and cholesterol total level [12]. This study was consistent with a previous study which stated that self-efficacy and adherence in exercise behavior significantly lower blood pressure level in patients with hypertension [13].

\section{CONCLUSION}

The results of this study clearly indicate the positive impact of relaxation progressive muscle program on exercise behavior, blood pressure level and cholesterol total level. This findings indicated that encouraging hypertension patients to adopt and implement the program in the daily living. Health care providers also should focus in promoting this program among patients with hypertension.

\section{ACKNOWLEDGEMENTS}

This study was supported by the research fund from the committee of research unit of Yarsi Nursing College, Pontianak.

\section{REFERENCES}

[1] American Heart Association (AHA), "Top contributing factors to high blood pressure-know your risk," 2012.

[2] K. Sliwa, et al., "Review: Hypertension and hypertensive hearth disease in African women," Clinical Respiratory Cardiology, vol. 103, pp. 515-523, 2014.

[3] T. S. Geraci and S. A. Geraci, "Review article: consideration in women with hypertension," The Southen Medical Association, 2013

[4] S. Lewington and R. Clarke, "Combine effect of systolic blood pressure and total cholesterol on cardiovascular diseases risk," American Heart Association, vol. 112, pp. 3373-3374, 2016.

[5] A. Bandura, "Self-efficacy. In V. S. Ramachaudran (Ed.)," Encyclopedia of Human Behavior, New York: Academic Press, pp. 71-81, 1994.

[6] A. Azizan, et al., "Effect of a behavioral program on exercise adherence and exercise self-efficacy in Community Dwelling Older Persons," Current Gerontology and Geriatrics Research, 2013.

[7] F. H. Kanfer and L. G. Buys, "Self-management methods," in F. H. Kanfer and A. P Goldstein (eds.), "Helping people change: A textbook of methods," New York: Pergamon Press, pp. 305-360, 1991.

[8] R. D. Grave, et al., "Review Article: Cognitive-Behavioral Strategies to Increase the Adherence to Exercise in the Management of Obesity," Journal of Obesity, pp. 1- 11, 2010.

[9] E. Hemmingsson, et al., "Influencing adherence to physical activity behavior change in obese adults," Scandinavian Journal of Nutrition/Narsing for skning, vol. 45, pp. 114-119, 2001

[10] R. A. Pamungkas, et al., "Dietary behavior among Muslim patients with poorly controlled type 2 DM in a community setting in Indonesia, 2015.

[11] S. R. Colberg, et al., "Exercise and Type 2 Diabetes," Diabetes Care, vol. 33, pp. e147-e167, 2010.

[12] R. J. Sigal, et al., "Clinical practice guidelines: physical activity and diabetes," Canadian Journal of Diabete, vol. 37, pp. S40-S44, 2013.

[13] T. J. Criswell, et al., "Effect of self-efficacy and social support on adherence to antihypertensive drugs," Pharmacotherapy, vol/issue: 30(5), pp. 432-441, 2010. 